INTERNATIONAL JOURNAL OF SCIENTIFIC RESEARCH

\title{
CLINICAL EVALUATION OF LAPAROSCOPIC CHOLECYSTECTOMY \\ WITH REFERENCE TO CONVERSION RATE AND COMPLICATIONS- OUR EXPERIENCE IN A TERTIARY CARE CENTRE OF EASTERN INDIA
}

\section{General Surgery}

\section{Swapnil Sen*}

MBBS, DNB (General Surgery), FIAGES, Senior Resident, Department of General Surgery, Vivekananda Institute of Medical Sciences, West Bengal University of Health Sciences, Kolkata. ${ }^{*}$ Corresponding Author

\section{Sandeep Kumar}

MBBS, DNB (General Surgery), Senior Resident, Department of General

Surgery, Shaheed Hasan Khan Mewati Govt. Medical College, Nalhar Nuh, Health University, Rohtak

\section{ABSTRACT}

Cholelithiasis is one of the most common surgical conditions requiring intervention worldwide. Since its introduction nearly four decades ago, laparoscopic cholecystectomy has become the gold standard of treatment for gallstone disease

AIM: To critically evaluate our experience of laparoscopic cholecystectomy in a tertiary care centre of eastern India.

MATERIALS AND METHODS: Hospital based observational study on 180 patients subjected to elective laparoscopic cholecystectomy with features of gall stone disease and meeting the inclusion and exclusion criteria.

RESULTS: Our conversion rate of $10 \%$ is somewhat higher than that reported in any other series. This probably reflects that few of our surgeons are in their early learning curve. This can be reduced with the experience of the surgeons. A bile duct injury rate of $0.5 \%$ compares favourably with an incidence of $0-1 \%$ in several large series. Overall complication rate of $5.5 \%$ also compares favourably with an incidence of $1.6-8.6 \%$ in several large series.

CONCLUSION:Laparoscopic cholecystectomy when performed in properly selected patients is very much effective in the treatment of symptomatic cholelithiasis - in terms of earlier return of bowel function, less postoperative pain, improved cosmesis, shorter length of hospital stay, earlier return of full activity and decreased overall cost. It is vital for the surgeons and patients to understand that conversion to open surgery is not failure; in fact, it implies a safe approach and a sound surgical judgment. The conversion rate is low with experienced surgeons indicating direct relationship between experience and conversion. It should be stressed that conversion if required should be done early rather than after an imminent complication.

\section{KEYWORDS}

laparoscopic cholecystectomy; open cholecystectomy, gall stone disease

\section{INTRODUCTION}

Cholelithiasis is one of the most common surgical condition requiring intervention worldwide. Since its introduction nearly four decades ago, laparoscopic cholecystectomy has become the gold standard of treatment for gallstone disease ${ }^{(1)}$. In March 1987, in France, Mouret performed the first laparoscopic cholecystectomy.

A National Institute of Health Consensus Development Conference in 1992, stated that laparoscopic cholecystectomy provides a safe and effective treatment for most patients with symptomatic gallstones. ${ }^{(2)}$ Because of its accompanying smaller incisions, less pain, short hospital stay, early return of bowel function, earlier return of full activity, and decreased overall cost $\mathrm{t}^{(3,4)}$ of operation make laparoscopic cholecystectomy more suitable over open cholecystectomy.

The result of laparoscopic cholecystectomy in specialized centres is excellent, where the rate of conversion to open procedure has ranged from $1.8 \%$ to $4.7 \%$. A number of factors are responsible that increase the chances of converting a laparoscopic procedure to an open one. Some of the factors are age, male sex, multiple acute attacks of biliary colic and acute cholecystitis, previous upper abdominal surgery, diabetes. Conversion rate is somewhat higher with less experienced surgeons. Common bile duct injury is a very unwelcoming event during laparoscopic cholecystectomy. The overall incidence of common bile duct injury is higher in laparoscopic cholecystectomy as compared to open approach. The incidence rate is $<0.5 \%$.

Overall outcome of laparoscopic cholecystectomy to a large extent is influenced by training, experience, ${ }^{(5,6)}$ skill and judgement of surgeon performing the procedure.

Less specialised centres, surgeons in their early learning phase, chronically fibrosed Calot's triangle, acute cholecystitis ${ }^{(7)}$ and obesity are some of the risk factors which make the common bile duct more prone to injury during laparoscopic cholecystectomy. ${ }^{(8-12)}$

\section{AIMS AND OBJECTIVES}

1. To critically evaluate our early experience in laparoscopic cholecystectomy with particular emphasis on

- History
- Clinical Findings

- Ultrasonography Findings

- Liver Function Test

- Operative Findings

- Operative Difficulties

- Conversion

- Complications

- Short term Follow-Up

2. To frame a protocol for laparoscopic cholecystectomy in our setup as regards -

- Case selection

- Procedural modification required, if any

- Training schedule

3. To compare our results with others.

\section{MATERIALS AND METHODS}

INCLUSION CRITERIA:

1. Age $15-65$ yrs

2. Gall stone disease

\section{EXCLUSION CRITERIA:}

1. Patients declared unfit for general anaesthesia or those with refractory coagulopathy, suspicion of malignancy, previous upper abdominal surgery, cholangitis, diffuse peritonitis, cirrhosis and/or portal hypertension, Chronic Obstructive Pulmonary Disease, cholecysto-enteric fistula, morbid obesity and pregnancy.

2. Patients having history of jaundice/ $\uparrow$ alkaline phosphatase/ dilated CBD on USG

3. Patients with history of obstructive biliopathy, gall stone pancreatitis, dilated intra hepatic biliary channels on USG.

\section{Methods:}

The history, examination findings, records of lab investigations, the operative details and postoperative significant events were recorded in detail in a prescribed proforma.

Regular follow up of all the patients was done in OPD at regular intervals after discharge and follow up particulars were recorded in the proforma. 
All the Laparoscopic Cholecystectomy operations were done in our operation theatre on elective basis under the Department of Surgery, B R Singh hospital, Sealdah, Kolkata.

All patients subjected to elective laparoscopic cholecystectomy performed in B R Singh Hospital, eastern railways, sealdah, Kolkata meeting the inclusion and exclusion criteria during 18 months of study period. The total number of patients under the study was 180

Study Duration: 01 October 2015 to 01 April 2017.

\section{RESULTS AND ANALYSIS}

\section{A. Age distribution}

Table-1

\begin{tabular}{|c|c|c|c|}
\hline $\begin{array}{c}\text { Age } \\
\text { group } \\
\text { (in yr) }\end{array}$ & $\begin{array}{c}\text { Total no. of } \\
\text { patients }\end{array}$ & $\begin{array}{c}\text { No. of patients } \\
\text { successfully done } \\
\text { Laparoscopically }\end{array}$ & $\begin{array}{c}\text { No. of patients } \\
\text { converted to open } \\
\text { procedure }\end{array}$ \\
\hline $15-25$ & $37(18.5 \%)$ & $35(19.3 \%)$ & $2(10.5 \%)$ \\
\hline $26-35$ & $58(29 \%)$ & $50(27.6 \%)$ & $8(42.1 \%)$ \\
\hline $36-45$ & $79(39.5 \%)$ & $72(40 \%)$ & $7(31.5 \%)$ \\
\hline$>45$ & $26(13 \%)$ & $23(12.7 \%)$ & $3(15.7 \%)$ \\
\hline
\end{tabular}

Patients of extreme age were not included in our study. Patients from 15 years to 65 years were taken in our study.

\section{B. Sex distribution}

Male female ratio is 1:5.7 in the whole group. Out of the ones which were converted to open procedure, $60 \%$ were males and $40 \%$ were females.

\section{Symptoms distribution}

Table-2

\begin{tabular}{|l|l|l|l|}
\hline Symptom & $\begin{array}{l}\text { Total no. } \\
\text { of patients }\end{array}$ & $\begin{array}{l}\text { No. of patients } \\
\text { successfully done } \\
\text { Laparoscopically }\end{array}$ & $\begin{array}{l}\text { No. of patients } \\
\text { converted to } \\
\text { open } \\
\text { procedure }\end{array}$ \\
\hline Acute Cholecystitis & $52(26 \%)$ & $32(17.8 \%)$ & $20(100 \%)$ \\
\hline Biliary colic & $118(59 \%)$ & $118(65.5 \%)$ & - \\
\hline Biliary dyspepsia & $30(15 \%)$ & $30(16.7 \%)$ & - \\
\hline
\end{tabular}

\section{Operative findings :}

Table 3

\begin{tabular}{|l|l|}
\hline Normal anatomy & 66 \\
\hline Long Cystic Duct & 20 \\
\hline Short Cystic Duct & 12 \\
\hline Accessory Cystic Duct & 4 \\
\hline Cystic Duct opening into right sectoral Duct & 5 \\
\hline Left Insertion of Cystic Duct & 5 \\
\hline Right Hepatic Artery Loop & 5 \\
\hline Posterior Cystic Artery & 4 \\
\hline Accessory Cystic Artery & 5 \\
\hline Frozen Calot's triangle & 10 \\
\hline Shrunken GB & 18 \\
\hline Uncontrolled bleeding & 4 \\
\hline Excessive adhesions at pericholecystic region & 12 \\
\hline Unclear anatomy & 8 \\
\hline Insufficient gas & 1 \\
\hline Adhesions of GB with duodenum & 1 \\
\hline
\end{tabular}

E. Spillage: In 32 cases $(17.8 \%)$, out of 180 successful laparoscopic cholecystectomies, there was spillage of bile or stones, but no major complications was reported in the postoperative period.

\section{F. Duration of Operation:}

Table 4

\begin{tabular}{|c|c|c|c|}
\hline Duration & \multicolumn{3}{|c|}{ No of cases } \\
\hline \begin{tabular}{|c|}
$<60 \mathrm{~min}$ \\
\end{tabular} & 5 & & \\
\hline$>60-90 \mathrm{~min}$ & 65 & $106(58.8 \%)$ & $161(89.4 \%)$ \\
\hline$>90-120 \mathrm{~min}$ & 36 & & \\
\hline$>120-150 \mathrm{~min}$ & 55 & & \\
\hline$>150-180 \mathrm{~min}$ & 14 & & \\
\hline$>180 \mathrm{~min}$ & 5 & & \\
\hline
\end{tabular}

\section{Mean operative time 109.6 minutes}

$58.8 \%$ of our cases were completed within 120 minutes. $89.4 \%$ of our cases were completed within 150 minutes.

\section{G. Duration of parenteral fluid therapy}

In 176 of our patients IV fluid was omitted within $24 \mathrm{hrs}$. Only 4 of our patients who required fluid for more than $24 \mathrm{hrs}$ were due to severe vomiting, delay in the return of bowel movements.

\section{H. Time for first oral feed:}

We allow plain water per orally after 4 hours of surgery initially which is then followed by liquid diet in the form of soup, coconut water, etc in next 24 hours of postoperative period. Only 4 patients had delay in starting first oral feed.

\section{No of parenteral analgesic dose:}

In our study, except in the first 24 hours when three doses of Inj. Paracetamol $1 \mathrm{gm}$ are given routinely, other doses are given on demand basis.

\section{J. Duration of Hospital Stay:}

Out of 180 laparoscopic cholecystectomies, only 6 cases were there who required a hospital stay of more than 3 days. Most of our patients were discharged within 3 days duration of postoperative period. 145 were discharged within the first 48 hours of operation.

\section{K. Complications \\ 1. Minor}

- Respiratory tract infection -7 patients

- Urinary retention -6 patients

- Vomiting-4 patients

- Right shoulder tip pain- 8 patients

2. Major

Table -5

\begin{tabular}{|l|l|l|}
\hline Haemorrhage & 1 & $0.5 \%$ \\
\hline Port site infection & 5 & $2.5 \%$ \\
\hline Bile leak & 2 & $1 \%$ \\
\hline Biloma & 1 & $0.5 \%$ \\
\hline Duodenal injury & 1 & $0.5 \%$ \\
\hline CBD injury & 1 & $0.5 \%$ \\
\hline Total & 11 & $5.5 \%$ \\
\hline
\end{tabular}

L.Conversion to open procedure

Table-6

\begin{tabular}{|c|c|c|c|c|c|}
\hline SI.No. & Age & Sex & Body weight & Symptoms & Cause \\
\hline 1 & 19 & $\mathrm{~F}$ & 46 & Ac. chole & Frozen Calot's triangle \\
\hline 2 & 28 & $\mathrm{M}$ & 68 & Ac. chole & shrunken gall bladder \\
\hline 3 & 23 & $\mathrm{M}$ & 76 & $\begin{array}{c}\text { Mirizzi } \\
\text { syndrome }\end{array}$ & Frozen Calot's triangle \\
\hline 4 & 30 & $\mathrm{M}$ & 74 & Ac. chole & Uncontrolled bleeding \\
\hline 5 & \begin{tabular}{|l|}
41 \\
41
\end{tabular} & $\mathrm{M}$ & 66 & Ac. chole & $\begin{array}{l}\text { Dense pericholecystic } \\
\text { adhesions }\end{array}$ \\
\hline 6 & 52 & $\mathrm{~F}$ & 49 & Ac. chole & shrunken gall bladder \\
\hline 7 & 59 & $\mathrm{M}$ & 78 & Ac. chole & Unclear anatomy \\
\hline 8 & 31 & $\mathrm{~F}$ & 58 & \begin{tabular}{|c|} 
chronic \\
chole with \\
diabetes
\end{tabular} & Frozen Calot's triangle \\
\hline 9 & 42 & $\mathrm{M}$ & 73 & $\begin{array}{l}\text { Chronic } \\
\text { chole }\end{array}$ & Insufficient gas \\
\hline 10 & 26 & $\mathrm{~F}$ & 57 & \begin{tabular}{|c|} 
Ac. Chole - \\
multiple \\
past attacks \\
of pain \\
abdomen
\end{tabular} & Uncontrolled bleeding \\
\hline 11 & 40 & $\mathrm{~F}$ & 60 & \begin{tabular}{|c|} 
Ac. Chole \\
with \\
diabetes \\
\end{tabular} & Frozen Calot's triangle \\
\hline 12 & 50 & $\mathrm{M}$ & 79 & Ac. chole & Instrument failure \\
\hline 13 & 33 & $\mathrm{M}$ & 88 & Ac. chole & $\begin{array}{c}\text { Adhesions of GB with } \\
\text { duodenum }\end{array}$ \\
\hline 14 & 44 & $\mathrm{~F}$ & 59 & $\begin{array}{l}\text { Cystic } \\
\text { artery } \\
\text { injury }\end{array}$ & Uncontrolled bleeding \\
\hline
\end{tabular}




\begin{tabular}{|c|c|c|c|c|c|}
\hline 15 & 39 & M & 92 & Ac. chole & Frozen Calot's triangle \\
\hline 16 & 27 & F & 58 & Ac. chole & Unclear anatomy \\
\hline 17 & 37 & M & 80 & Ac. chole & Frozen Calot's triangle \\
\hline 18 & 35 & F & 50 & Ac. chole & Subphrenitis \\
\hline 19 & 31 & M & 60 & Ac. chole & Unclear anatomy \\
\hline 20 & 39 & M & 48 & Ac. chole & $\begin{array}{l}\text { Excessive adhesions at } \\
\text { pericholecystic region }\end{array}$ \\
\hline
\end{tabular}

\section{DISCUSSION}

Evaluation of our experience with laparoscopic cholecystectomy during our training:

a. Age distribution: Patients in age group of 26-35 years are more to undergo laparoscopic cholecystectomy and next in age group of $36-45$ years. There is a male preponderance of higher age group in those who were converted to open procedure.

b. Sex distribution: As a whole females are at more risk having cholelithiasis. On the other hand males are more prone to get converted to open procedure.

c. Body Wt. Distribution: Weight is directly related to chances of open conversion

d. Symptom distribution: Recurrent attacks of acute cholecystitis are associated with high chances of conversion were shown by our study.

e. Duration of operation: There is definite decrease of operative time with the experience of the surgeons.

f. Duration of parenteral fluid: IV fluids were not used for more than $24 \mathrm{hrs}$ in most of our patients. Only 4 patients were there in whom fluids were required for more than $24 \mathrm{hrs}$.

g. Time of first oral fluid: Plain water was tolerated with ease within 4 hrs post operatively. Liquid diet was given within $24 \mathrm{hrs}$ of operation which was tolerated well.

h. Doses of parenteral analgesics: Most of our patients required 3 doses of inj. Paracetamol $1 \mathrm{gm}$. Only 8 patients required more than 3 doses.

i. Duration of Hospital Stay : Most of our patients could be discharged on the $2^{\text {nd }}$ post operative day.

j. Complications :-

- No mortality occurred in our study.

- 8 patients suffered pneumoperitonium related shoulder tip pain in our study.

- Of general complications 4 of our patients had severe vomiting post operatively for which IV fluid had to be continued and it was controlled with IV ondansetron. 6 had retention of urine for which foley's catheterization was done. 7 patients developed respiratory infection which subsided with oral antibiotics and spirometry.

- In our study there was no case of trocar related injury.

- 3 cases had to be converted to Open Cholecystectomy for uncontrolled haemorrhage- mostly due to tear of cystic artery during dissection. Injury to an unrecognised additional branch of cystic artery was the cause of bleeding in one of the case. One of the patients was found in shock with collection in the abdominal drain. Patient was taken to OT for exploration on the same day. There was collection of blood clot in the hepatorenal pouch along with oozing from liver bed. Haemostasis was secured and a drain was placed. Postoperative recovery was good.

- There was spillage of bile and stone in $17.8 \%$ of cases in our study. These cases recovered uneventfully. A single dose of Inj. Amikacin-1g i.v. was administered in these cases. In majority of cases stones were removed but in 4 cases some of them could not be removed. There were 5 cases of port site infection.

- 1 case of duodenal injury was there unfortunately. This patient had a history of recurrent acute attacks. There was dense pericholecystic adhesions and at Calot's triangle. The adhesions were lysed. No cholecystoduodenal fistula was detected at the time of operation. But on first postoperative day patient complained of pain with abdominal distension and developed features of peritonitis. This case was reexplored on the $3^{\text {rd }}$ postoperative day and a small duodenal perforation was detected at the site of previous adhesion. Simple one layer closure was done with omental patch. Postoperative recovery was uneventful.

- Two cases of bile leak subsided on conservative management.

- There was one case of biloma in our study. Patient was discharged and readmitted on $15^{\text {th }}$ postoperative day with abdominal lump in right hypochondrium and sluggish peristalsis. The case was reexplored the next day and a huge collection of bile was seen in the hepatorenal pouch. A drain was placed. The bile flow gradually subsided. The drain was removed after 2 weeks.
- There was one case of lateral CBD injury in our study. Patient complained of pain abdomen with jaundice after 2 weeks. CBD stenting was done via ERCP. Patient was re-operated after 2 months and a Roux en Y Hepaticojejunostomy was done. Post operative period was uneventful.

k. Conversion rate: The overall conversion rate of $10 \%$ was somewhat higher than that reported in many previous series.

l. Follow-up: Follow-up was short. The period extended from 3 months to 9 months. In this period no patient in our follow-up had any major complication like port site hernia, complications due to retained stones, etc.

2. To frame a standard protocol for Laparoscopic Cholecystectomy in our set up as regards:-

\section{- Case selection}

Our Institution is a post Graduate Teaching Institution having post graduate students in general surgery. So for proper exposure of post graduate students Open and laparoscopic Cholecystectomy have to run side by side. Moreover, as few of the surgeons here during my study period were at their early learning phase, we have kept uncomplicated cases for Laparoscopic Cholecystectomy and complicated cases (both from the stand point of anaesthesia and surgery) and the cases where there is indication for CBD exploration from history, LFT and USG findings, were prepared for Open Cholecystectomy.

- Procedural modification required, if any

No procedural modification is required but we suggest few points to avoid complications

- For Veress insertion by close technique always lift the skin with other hand or towel clips, and during insertion of first trocar aim should be towards pelvic cavity and not towards spine to avoid injury to great vessels. Open procedure of first port entry was an equally good procedure.

- For good exposure of cystic duct, gall bladder should be pushed in cephalad direction towards right shoulder.

- Lateral traction on the infundibulum of the Gall bladder to place the cystic duct perpendicular to the common duct.

- Aim should be minimum handling of CBD which can be achieved by dissection of cystic duct at the infundibulum.

- To demonstrate the junction of cystic duct and infundibulum posterior biliary window should be created by medial traction of the infundibulum

- No diathermy should be used near CBD

- No blind attempts at controlling bleeding with cautery or clips.

- Strassberg's critical view of safety should be achieved in all cases of laparoscopic cholecystectomy.

- No hesitation technique should be used for conversion to open if anatomical relationship in Calot's triangle cannot be defined or any injury to CBD or other structures are suspected. Conversion to open procedure should not be considered as a demerit.

We would also suggest infrastructure upgradation for development of Laparoscopic Cholecystectomy in our Institution.

- Per operative cholangiogram.

- Laparoscopic and intraoperative Ultrasonography.

- Training schedule

- Two categories of training

- Basic laparoscopy - which include laparoscopic cholecystectomy, appendectomy and diagnostic laparoscopy.

- Advanced laparoscopy includes Laparoscopic hernia repair, colectomies, etc.

- Two strata of training

- to train faculty member

- to train resident surgeons and Post graduate students.

\section{To compare our results with others :-}

Our conversion rate of $10 \%$ is somewhat higher than that reported in any other series. This probably reflects that few of our surgeons are in their early learning curve. This can be reduced with the experience of the surgeons. A bile duct injury rate of $0.5 \%$ compares favourably with an incidence of $0-1 \%$ in several large series. Overall complication rate of $5.5 \%$ also compares favourably with an incidence of $1.6-8.6 \%$ in several large series.

\section{CONCLUSION}

Laparoscopic cholecystectomy was introduced three decades ago by a 
German surgeon. It took little time for surgeons and patients across the globe in accepting it as gold standard treatment for gallstone disease. Conversion to open surgery is a major morbidity for patients as the advantages of laparoscopy is lost.

In the current study, the commonest cause for conversion to open procedure was dense adhesions in Calot's triangle (30\%). Adhesions are defined as scar tissue which develops in response to prior surgery, trauma, or inflammation. Due to dense adhesions, clear identification of cystic duct and cystic artery was not possible leading to conversion. Other causes included uncontrolled bleeding, instrument failure, duodenal injury and generalized adhesions due to previous upper abdominal surgery. Other reasons reported in this study included technical difficulties, iatrogenic injuries, severe acute inflammation, bleeding, bile leak, and choledochoduodenal adhesions in decreasing order.

History of previous abdominal surgery especially upper abdominal surgery can be a cause of conversion to open procedure. In our study, we converted one procedure due to severe generalized adhesions following previous upper abdominal surgery. It was deemed extremely unsafe to proceed, thus immediate decision to proceed with open surgery was undertaken.

With growing experience of Laparoscopic cholecystectomy, the conversion rates around the world are falling. Still a proportion of patients need conversion to open procedure due to multiple factors ranging from difficult dissection to iatrogenic injuries. Different conversion rates have been mentioned in literature ranging from 2.7$19 \%$. However, the rate of conversion is high in studies from the Asian countries as compared to those from western world. Our conversion rate is $10 \%$ which is a bit higher than the conversion rates reported in the literature.

It is vital for the surgeons and patients to understand that conversion to open surgery is not failure; in fact, it implies safe approach and a sound surgical judgment. The conversion rate is low in experienced surgeons indicating direct relationship between experience and conversion. It should be stressed that conversion if required should be done early rather than after an imminent complication.

Iatrogenic injuries like Common Bile Duct injury, injury to cystic artery or hepatic artery with uncontrollable bleeding, Bowel injury, gallbladder perforation with spillage of stones in the abdominal cavity are all reported to have led to conversion. In our study, two iatrogenic complications were encountered post-operatively in the form of Common Bile Duct and duodenal injury.

In cases where safe identification did not lead to positive identification of cystic duct and artery, we performed a subtotal cholecystectomy.

In our study, instrument failure, has been reported as a reason for conversion. One case happened in our study due to unavailability of replacement instruments.

Middle age, male gender, higher body weight is also more prone to get converted to open.

In our study, we found that laparoscopic cholecystectomy when performed in properly selected patients is very much effective in the treatment of symptomatic cholelithiasis - in terms of earlier return of bowel function, less postoperative pain, improved cosmesis, shorter length of hospital stay, earlier return of full activity and decreased overall cost.

If a policy of 'no hesitation' in converting to open procedure is followed, especially in the early phase of a surgeon's experience, although there may be higher conversion rate, the complication rate will be within acceptable limits.

\section{CONFLICT OF INTEREST:}

The authors declare that there is no conflict of interest.

\section{REFERENCES:}

1. Soper N, Stockmann P, Dunnegan D. Laparoscopic cholecystectomy: the new "gold Soper N, Stockmann P, Dunnegan D. Laparoscopic

2. NIH Consensus conference. Gallstones and laparoscopic cholecystectomy. JAMA: The Journal of the American Medical Association. 1993;269(8):1018-1024.

3. Soper N, Barteau J, Clayman R. Comparison of early postoperative results for laparoscopic versus standard open cholecystectomy. Surgery, Gynaecology and Obstetrics. 1992;174(2):114-118

4. Bass E, Lillemoe K, Pitt H. Cost effectiveness of laparoscopic cholecystectomy versus open cholecystectomy. American journal of surgery. 1993;165(4):466-471.

5. Nengl J. A prospective analysis of 1518 laparoscopic cholecystectomies. The SogeonsClub.uthern Sur. New England JOURNAL of Medicine. 1991;324(16):10731078

6. Dubois F, Cuschieri A. The European experience with laparoscopic cholecystectomy American Journal of Surgery. 1991;161(3):385-387

7. Sanabria J, Croxford R, Strasberg S, Gallinger S. Risk factors in elective laparoscopic cholecystectomy for conversion to open cholecystectomy. Journal of American College of Surgeons. 1994;179(6):696-704.

8. Mcsherry C. Cholecystectomy: the gold standard. American journal of surgery. 1989;158:174-178.

9. Roslyn J, Binns G, Hughes E, Saunders-Kirkwood K, Zinner M, Cates J. Open Cholecystectomy A Contemporary Analysis of 42,474 Patients. Annals of Surgery. 1993;218(2):129-137.

10. Moossa A, Easter D, Sonnenberg E, Casola G, D agostino H. Laparoscopic Injuries to the Bile Duct. Annals of Surgery. 1992;215(3):203-208

11. New York state department of health memorandum series. laparoscopic surgery. New York; 1992 p. $92-201$

12. Rossi R. Laparoscopic Bile Duct Injuries Risk Factors, Recognition, and Repair. Archives of Surgery. 1992;127(5):596. 